\title{
Large-Scale State Transition
}

National Cancer Institute

\section{Source}

National Cancer Institute. Large-Scale State Transition. NCI Thesaurus. Code C120466.

Chromosomal breakage that generates $10 \mathrm{Mb}$ or larger fragments. The quantification of these breaks can be used as a surrog ate measure for genomic instability, which may be caused by mutation of DNA repair genes, including BRCA1 or BRCA2. 